\title{
Multiple Myeloma Management in COVID-19 Era
}

\author{
Andree Kurniawan ${ }^{1, \odot}$ Devina Adella Halim², $\quad$ Noorwati Sutandyo ${ }^{3, \odot}$
}

${ }^{1}$ Department of Internal Medicine, Faculty of Medicine, Pelita Harapan University, Banten, Indonesia

${ }^{2}$ Faculty of Medicine, Pelita Harapan University, Banten, Indonesia

${ }^{3}$ Hematology and Medical Oncology Department, Dharmais Cancer Hospital, Jakarta, Indonesia

\begin{abstract}
Address for correspondence Andree Kurniawan, MD, Department of Internal Medicine, Faculty of Medicine, Pelita Harapan University, Boulevard Jendral Sudirman Karawaci, Tangerang, Banten 15811, Indonesia (e-mail: andree.kurniawan@uph.edu).
\end{abstract}

\begin{abstract}
Introduction Coronavirus disease 2019 (COVID-19) has become a world pandemic since early 2020. The complexity of handling multiple myeloma (MM) has increased substantially during this pandemic. The objective of this review is to know the current recommendation to manage MM in the COVID-19 era.

Materials and Methods Electronic databases, including PubMed central and PubMed, were used to conduct a literature search. It was conducted on May 18, 2020, using the keywords "multiple myeloma” AND "COVID-19" AND "Prevalence OR Impact OR treatment OR prophylactic." The included articles were review articles, recommendations, case reports or series, or population-based studies (cross-sectional, cohort, case-control, or interventional), and full-text if available.

Results A total of 124 articles were identified through the search strategy. The two reviewers screened titles and abstracts of all articles. Most articles were excluded because of ineligible to the criteria. Ultimately, 18 articles were included in the final evaluation. MM patients might have higher risk to become severe COVID-19 if they got infected due to their immunocompromised condition. Due to the pandemic, precise treatment priorities should be made by considering its benefit and the risk of MM progression. For the young, especially healthy patients, the most effective therapy should be offered and tailored to the patient's goal. Several MM societies have published the

Keywords

- COVID-19

- myeloma

- management recommendation regarding the special stage of MM.

Conclusion Myeloma societies in the world have released recommendations related to the management of myeloma patients. However, there is scarce of evidence to do the recommendation.
\end{abstract}

\section{Introduction}

Coronavirus disease 2019 (COVID-19) first emerged in Wuhan, China, in December 2019, and since then it has rapidly spread to almost all countries in the world. So far, COVID-19 has contracted more than 4.7 million patients in almost all countries and has become a major global health concern. Presently, the global mortality rate is $4.7 \%$, but it varied across countries. ${ }^{1}$ Multiple myeloma (MM) is a malignant plasma cell dyscrasia that predominantly affects the elderly and frail population. MM contributes to $1 \%$ of all cancer population and approximately $10 \%$ of hematological malignancies. Based on data, in Europe, there were 4.5 to 6 cases per 100,000 population per year and a mortality rate of 4.1 per 100,000 population. The median age of patients diagnosed with MM is 72 years. ${ }^{2,3}$ Mostly MM is diagnosed at a later age along with several comorbidities, and consequently corticosteroid is required to be a part of the therapy in all cases. Infections rate in MM including respiratory infections still significantly impact the rate of early mortality in this group of people. Due to the risk of severe published online July 8,2020
DOI https://doi.org/ $10.1055 / \mathrm{s}-0040-1716813$ ISSN 2454-6798. (c) 2020. Spring Hope Cancer Foundation \& Young Oncologist Group of Asia.

This is an open access article published by Thieme under the terms of the Creative Commons Attribution-NonDerivative-NonCommercial-License, permitting copying and reproduction so long as the original work is given appropriate credit. Contents may not be used for commercial purposes, or adapted, remixed, transformed or built upon. (https://creativecommons.org/licenses/by-nc-nd/4.0/)

Thieme Medical and Scientific Publishers Pvt. Ltd., A-12, 2nd Floor, Sector 2, Noida-201301 UP, India 
morbidity of COVID-19 infection, the challenges of handling MM have increased extensively amidst the pandemic. ${ }^{4}$ In these patients, the probability of developing severe case of COVID-19 is higher than healthy individuals without comorbidities. ${ }^{5}$ The latest evidence showed that the risk of COVID19 infection in cancer patients was the same as that in the normal population; however, cancer patients seemed to get severe complications of COVID-19 infection especially if they have recently undergone cancer treatment. ${ }^{6.7}$

To control the rapid spread of disease dissemination, public health measures are undertaken to decrease hospital visits and elective procedures. Nonetheless, cancer patients need to continue follow-up during the natural history of the disease. ${ }^{8}$ There are still limited data regarding the management of MM in this difficult situation. Several myeloma societies have released their statement regarding the myeloma management. The objective of this review is to know the current recommendation and other new evidence recently published regarding the management of MM in the COVID-19 era.

\section{Materials and Methods}

\section{Search Strategy}

A literature search of electronic databases, including PubMed and PubMed Central, was conducted on May 18, 2020, using the keywords "Multiple myeloma" AND "COVID-19" AND "Prevalence OR Impact OR Treatment OR Prophylactic." The literature search was performed using the inclusion of review articles, international recommendations, and observational study. Then, the titles and abstracts were found through each search engine. Type of included studies in this review were review article, recommendation, case report or series, or population studies (cross-sectional, cohort, case-control, or interventional). The timing of outcome is any time after the diagnosis of COVID-19 infection. Studies were excluded if MM was diagnosed after infection with COVID-19.

\section{Results and Discussion}

\section{Literature Results}

A total of 124 articles (113 articles from PMC and 11 articles from PubMed) were identified through the search strategy. - Fig. 1 shows the PRISMA (Preferred Reporting Items for Systematic Reviews and Meta-Analyses) diagram. The two reviewers screened the titles and abstracts of all articles. Most articles were excluded because due to ineligibility. Ultimately, 18 articles were included in the final evaluation.

\section{Incidence and the Impact of COVID-19 among Myeloma Patients}

Currently, no study evaluating the incidence of COVID-19 in myeloma patients was found. There was one cohort study at two centers in Wuhan, China, involving 128 hospitalized patients with hematological cancers, of whom 13 (10\%) contracted COVID-19 and 19 (15\%) were MM patients. Among the MM patients, three (15.5\%) were infected with COVID-19. ${ }^{9}$ Overall, 122 (95\%) out of 128 total patients received prior systemic therapies including molecular targeted therapy

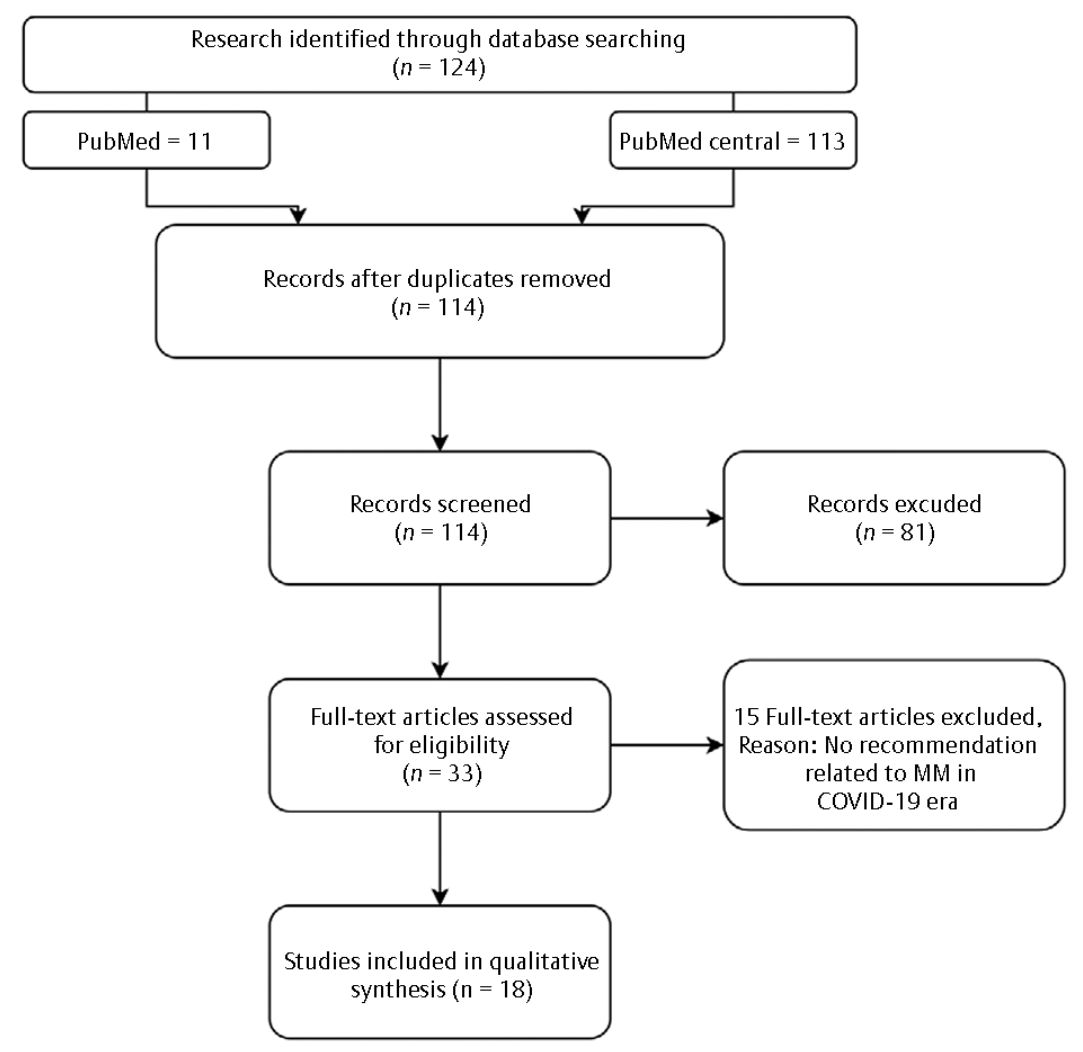

Fig. 1 PRISMA (Preferred Reporting Items for Systematic Reviews and Meta-Analyses) diagram literature search of the study. MM, multiple myeloma. 
$(N=9)$, chemotherapy $(N=96)$, immune therapy $(N=23)$, and a proteasome inhibitor $(N=9)$ before $(N=75)$ or after $(N=110)$ hospitalization. The median interval from the last systemic therapies to the establishment of COVID-19 diagnosis was 9 days (range: 7-19 days), and six patients received treatment that involved the bone marrow. ${ }^{9}$

The incidence of COVID-19 was found to be higher in hospitalized patients with hematological malignancies, which accounted for $10 \%$ (95\% confidence interval [CI]: 6-17) in comparison in health care providers, which accounted for $7 \%$ (95\% CI: 4-12; $p=0.0322$ ). Unfortunately, in contrast to the infected health care providers, more severe case of COVID-19 and higher mortality were found in 13 patients with hematological malignancies. ${ }^{9}$

\section{Features of Myeloma Patients Increasing Vulnerability/ Mortality}

Several features of MM patients were found to be similar to risk factors in severe COVID-19. Majority of the MM patients were male and elderly. ${ }^{10,11}$ It was frequent that MM patients have comorbidities such as chronic obstructive pulmonary disease, diabetes mellitus, hypertension, and chronic kidney disease. ${ }^{12}$ In several circumstances, MM patients will present with cytopenia, neutropenia, or lymphocytopenia. Thrombosis is a frequent feature in patients with MM, particularly those receiving immunomodulatory drug (IMID) treatment, for example, lenalidomide or thalidomide concomitantly with anthracyclines or dexamethasone. ${ }^{13}$

A study from Tongji Hospital in China revealed that in 269 patients with severe COVID-19 on admission, elderly population, male gender, comorbidity with hypertension, hyperglycemia, and high-dose corticosteroid use were associated with death. ${ }^{14}$ Severe COVID-19 patients presented with coagulation problems, mimicking other systemic coagulopathies such as disseminated intravascular coagulation (DIC) or thrombotic microangiopathy, were associated with severe cases. COVID-19 patients presenting with coagulopathy is associated with an increased risk of mortality. ${ }^{15}$

\section{The Impacts of COVID-19 in Cancer Care}

Many information and regulations were recently released, and, consequently, the oncology service was affected globally. Performing the oncology care was more challenging and complicated by the fact that many health care staffs contracted COVID-19 infection..$^{16}$ The delivery of cancer care could be disrupted. Cancer clinics need to reduce clinical appointments. Chemotherapy administrations, altered radiotherapy schedules, and elective surgery would be canceled. ${ }^{17}$ There might be shortage of supplies, and nonavailability of drugs and consumables. Newly diagnosed or existing cancer patients who experience lung problems might be denied care due to heightened suspicious to COVID-19 infection. The patient management of cancer-related symptoms, quality of life, and survival will be disrupted. ${ }^{18-20}$

\section{Approach to Myeloma Patients during COVID-19 Era}

The general principles are to reduce hospital visit needs. Patients should be evaluated if there are signs of upper respiratory tract infection or fever when they come to the hospital. Patients are only invited to come to the hospital if the absence of the aforementioned symptom was confirmed. If it is mandatory, face-to-face visit with MM patients without accompanying caregivers were allowed to assess vital signs and question about their exposure history in detail. In symptomatic patients, a swab test should be performed. Blood samples can be obtained in the outpatient clinic or in the drive-through cars. Other consultations should be managed with telemedicine format by video or phone calls. ${ }^{21}$

Due to the pandemic, precise treatment priorities should be made by considering its benefit and the risk of MM progression. It was divided into high, medium, and low priority. The newly diagnosed, relapsed, or refractory MM patients should be stratified according to the indication for an autologous stem cell transplant (ASCT). All patients coming for inpatient care must be screened for COVID-19 infection. Patients who underwent intensive therapy, for instance, stem cell transplantation or CAR (chimeric antigen receptor) $\mathrm{T}$-cell therapy, have to be in quarantine for 14 days before the beginning of the therapy. ${ }^{21}$

\section{General Recommendation for MM Patients}

The International Myeloma Society (IMS) has shared several consensuses for myeloma patient care in the middle of the COVID-19 outbreak. Due to their weak immune system, all MM patients should be aware of their susceptibility to COVID-19 infection. They should adhere to the infection prevention recommendation, as well as physical distancing, hand hygiene practice, avoiding travel (except for treatment), and limited contacts. ${ }^{22}$

Therapeutic decision should be discussed, considering the disease stage, risk, frontline versus relapse, cytogenetics/ FISH, age, and comorbidities. Do limit patients' contact while undergoing therapy and prescribe oral drugs as much as possible (IMIDs or oral proteasome inhibitor if available). If intravenous drugs are used, consider to decrease the frequent use. Dexamethasone treatment should also be reduced. ${ }^{22}$

\section{Approach to Newly Diagnosed Young and Transplant-Eligible MM Patients}

In patients who are newly diagnosed, it is important to discuss with patients and their family about the goals of care. The priorities of newly diagnosed, young, and transplant-eligible MM patients are given in - Table 1. For the young, especially healthy patients, the most effective therapy should be offered and tailored to patients' goal and further step. Before the COVID-19 era, transplant was often recommended for newly diagnosed patients. During the pandemic, the therapeutic decision should be discussed. Before undergoing chemotherapy, preventive measures including granulocyte colony-stimulating factor (G-CSF) to minimize neutropenia side effects should be taken. ${ }^{22}$ Frontline ASCT should be postponed if possible. Patients should be evaluated for COVID-19 before undergoing ASCT. Induction regimen can include up to six cycles; and for standard-risk patients, it is possible to delay ASCT by additional induction cycles and/or lenalidomide 
Table 1 Priorities for newly diagnosed young and transplant-eligible multiple myeloma patients

\begin{tabular}{|c|c|c|}
\hline High priority & Medium priority & Low priority \\
\hline $\begin{array}{l}\text { Patients with a recent diagnosis of } \\
\text { active/high-risk disease } \\
\text { (SLIM-CRAB criteria present): } \\
\text { - therapy should not be deferred } \\
\text { - therapeutic decisions should be } \\
\text { made on a case-by-case basis } \\
\text { based on disease stage, risk, age, } \\
\text { cytogenetics/FISH, comorbidities } \\
\text { - consider G-CSF support to mini- } \\
\text { mize the risk of neutropenia }\end{array}$ & $\begin{array}{l}\text { Patients on continuous first-line treatment: } \\
\text { - consider to postpone ASCT and prolong the induction regi- } \\
\text { men for up to six to eight cycles } \\
\text { - scheduled patients to undergo ASCT should be tested for } \\
\text { COVID-19 before ASCT } \\
\text { - for standard-risk patients, consider delaying ASCT by addi- } \\
\text { tional induction cycles and/or lenalidomide maintenance } \\
\text { - use interval phone and/or virtual visits whenever possible to } \\
\text { - monitor tolerability of treatment to decrease clinical visits } \\
\text { consider extending access to lenalidomide for up to } 2 \text { mo for } \\
\text { patients receiving maintenance therapy (with telemedicine/ } \\
\text { remote laboratory test in between) } \\
\text { - in patients in need of IVIG replacement, consider } \\
\text { administration at a reduced frequency } \\
\text { - consider G-CSF support to minimize neutropenia }\end{array}$ & $\begin{array}{l}\text { Patients in stable remission } \\
\text { (currently without active } \\
\text { treatment): } \\
\text { - postpone follow-up visits } \\
\text { and/or perform by } \\
\text { telemedicine if possible } \\
\text { - postpone antiresorptive } \\
\text { therapy (zoledronic acid, } \\
\text { denosumab) and/or } \\
\text { reduce the frequency } \\
\text { (e.g., every } 3 \text { mo) }\end{array}$ \\
\hline
\end{tabular}

Abbreviations: ASCT, autologous stem cell transplant; FISH, fluorescence in situ hybridization; G-CSF, granulocyte colony-stimulating factor; IVIG, intravenous immunoglobulin; S, $\geq 60 \%$ clonal BM plasma cells; Li, serum-free light chain ratio involved:uninvolved $\geq 100 ; \mathrm{M},>1 \mathrm{focal}$ lesion ( $\geq 5 \mathrm{~mm}$ each) detected by MRI studies; C, calcium elevation ( $>11 \mathrm{mg} / \mathrm{dL}$ or $>1 \mathrm{mg} / \mathrm{dL}$ higher than ULN); R, renal insufficiency (creatinine clearance $<40 \mathrm{~mL} / \mathrm{min}$ or serum creatinine $>2 \mathrm{mg} / \mathrm{dL}$ ); A, anemia $(\mathrm{Hb}<10 \mathrm{~g} / \mathrm{dL}$ or $2 \mathrm{~g} / \mathrm{dL}<$ normal); B, bone disease ( $\geq 1$ lytic lesions on skeletal radiography, CT, or PET-CT). Source: European Society of Medical Oncology. ${ }^{26}$

Table 2 Priorities for newly diagnosed elderly, transplant noneligible multiple myeloma patients

\begin{tabular}{|c|c|c|}
\hline High priority & Medium priority & Low priority \\
\hline $\begin{array}{l}\text { Patients with newly diagnosed } \\
\text { active/high-risk disease } \\
\text { (SLIM-CRAB criteria present): } \\
\text { - Treatment should not be } \\
\text { postponed } \\
\text { Therapeutic decisions should } \\
\text { be made on a case-by-case } \\
\text { basis, considering disease stage, } \\
\text { risk, age, cytogenetics/FISH, } \\
\text { comorbidities } \\
\text { - Consider G-CSF support to } \\
\text { minimize the risk of } \\
\text { neutropenia. }\end{array}$ & $\begin{array}{l}\text { Patients on continuous treatment: } \\
\text { - patients responding to lenalidomide-dexamethasone: } \\
\text { consider discontinuation of dexamethasone and } \\
\text { maintain response with lenalidomide alone } \\
\text { - prefer prescription of orally available drugs } \\
\text { - if parenteral drug administration is necessary, consider } \\
\text { - using it at a reduced frequency } \\
\text { - use interval phone and/or virtual visits whenever } \\
\text { - } \text { possible to monitor tolerability and outcome } \\
\text { - consider G-CSF support to minimize the risk of } \\
\text { neutropenia }\end{array}$ & $\begin{array}{l}\text { Patients in stable remission on } \\
\text { continuous treatment (or without active } \\
\text { treatment): } \\
\text { - delay follow-up visits and/or perform } \\
\text { by telemedicine if possible. } \\
\text { - delay antiresorptive therapy } \\
\text { (zoledronic acid, denosumab) and/ } \\
\text { or reduce the frequency (e.g., } \\
\text { every } 3 \text { mo) }\end{array}$ \\
\hline
\end{tabular}

Abbreviations: FISH, fluorescence in situ hybridization; G-CSF, granulocyte colony-stimulating factor; S, $\geq 60 \%$ clonal BM plasma cells; Li, serum-free light chain ratio involved:uninvolved $\geq 100 ; \mathrm{M},>1$ focal lesion $(\geq 5 \mathrm{~mm}$ each) detected by MRI studies; $\mathrm{C}$, calcium elevation $(>11 \mathrm{mg} / \mathrm{dL}$ or $>1 \mathrm{mg} / \mathrm{dL}$ higher than ULN); R, renal insufficiency (creatinine clearance $<40 \mathrm{~mL} / \mathrm{min}$ or serum creatinine $>2 \mathrm{mg} / \mathrm{dL}$ ); A, anemia $(\mathrm{Hb}<10 \mathrm{~g} / \mathrm{dL}$ or $2 \mathrm{~g} / \mathrm{dL}<\mathrm{normal}$ ); $B$, bone disease ( $\geq 1$ lytic lesions on skeletal radiography, CT, or PET-CT).

Source: European Society of Medical Oncology. ${ }^{26}$

maintenance. In patients with active or high-risk disease, treatment should not be postponed..$^{21,22}$

\section{Approach to Newly Diagnosed Elderly, Transplant Noneligible MM Patients}

The priorities for newly diagnosed elderly, transplant noneligible MM patients can be seen in more details in - Table 2. There are several recommendations from the IMS $^{22}$ for this group of patients. The treatment should be prescribed based on oral administration, for instance, weekly dose of lenalidomide-dexamethasone should be decreased to $20 \mathrm{mg}$. If there is good response to frontline therapy combining lenalidomide-dexamethasone, discontinue dexamethasone and maintain response with lenalidomide alone. ${ }^{22}$

\section{Approach to Relapse/Refractory MM Patients}

An essential topic that is needed to be discussed during this pandemic is the treatment options for the failures. For clinical and more aggressive relapses, the next recommended treatment cannot be postponed. However, for standard-risk patients, only laboratory relapsed without symptoms, postponing the subsequent treatment can be done if possible. ${ }^{23}$ The priorities for relapsed or refractory MM patients can be seen in detail in - Table 3. Similar recommendations were given by IMS in the upfront settings. In case of good response to a three-drug intravenous regimen, modify the treatment to minimize the need for coming to the hospital: first, using weekly regimens of carfilzomib or bortezomib, second, using oral agents such as ixazomib, if possible, and, third, changing to monthly treatment of daratumumab as soon as possible. ${ }^{22}$

\section{Approach to Newly Diagnosed MGUS and SMM Patients}

There is no disagreement regarding the management of standard-risk smoldering MM(SMM) patients. These patients should be monitored with no active intervention. The SMM patients have a higher rate of transformation of SMM to MM compared with the progression of monoclonal gammopathy 
Table 3 Priorities for relapsed/refractory multiple myeloma patients

\begin{tabular}{|c|c|c|}
\hline High priority & Medium priority & Low priority \\
\hline $\begin{array}{l}\text { Patients with relapsed disease requiring } \\
\text { therapy (development of new SLIM-CRAB } \\
\text { criteria or significant paraprotein relapse) or } \\
\text { refractory MM: } \\
\text { - therapy should not be postponed } \\
\text { - therapeutic decisions should be made } \\
\text { on a case-by-case basis, considering } \\
\text { disease stage, risk, cytogenetic/FISH, } \\
\text { age, comorbidities } \\
\text { - consider G-CSF support to minimize the } \\
\text { risk of neutropenia }\end{array}$ & $\begin{array}{l}\text { Patients with relapsed/refractory disease on } \\
\text { continuous treatment: } \\
\text { - in patients responding to lenalidomide/ } \\
\text { dexamethasone, consider modifying } \\
\text { the treatment regimen to minimize the } \\
\text { need for clinic/hospital visits, e.g., by: } \\
\text { - using weekly instead of biweekly admin- } \\
\text { istration of drugs (e.g., carfilzomib, } \\
\text { bortezomib) } \\
\text { - preference of oral agents (i.e., ixazomib, } \\
\text { lenalidomide, pomalidomide) } \\
\text { - switching to monthly administration of } \\
\text { daratumumab as soon as possible }\end{array}$ & $\begin{array}{l}\text { Patients with relapsed/refractory disease in } \\
\text { stable remission on continuous treatment: } \\
\text { - delay antiresorptive therapy (zoledronic } \\
\text { acid, denosumab) and/or reduce the } \\
\text { frequency (e.g., every } 3 \text { mo) }\end{array}$ \\
\hline
\end{tabular}

Abbreviations: FISH, fluorescence in situ hybridization; G-CSF, granulocyte colony-stimulating factor; MM, multiple myeloma; $\mathrm{S}, \geq 60 \%$ clonal BM plasma cells; Li, serum-free light chain ratio involved:uninvolved $\geq 100 ; \mathrm{M},>1$ focal lesion ( $\geq 5 \mathrm{~mm}$ each) detected by MRI studies; C, calcium elevation $(>11 \mathrm{mg} / \mathrm{dL}$ or $>1 \mathrm{mg} / \mathrm{dL}$ higher than ULN); R, renal insufficiency (creatinine clearance $<40 \mathrm{~mL} / \mathrm{min}$ or serum creatinine $>2 \mathrm{mg} / \mathrm{dL}$ ); A, anemia $(\mathrm{Hb}<10 \mathrm{~g} / \mathrm{dL}$ or $2 \mathrm{~g} / \mathrm{dL}<$ normal); B, bone disease ( $\geq 1$ lytic lesions on skeletal radiography, $\mathrm{CT}$, or PET-CT) .

Source: European Society of Medical Oncology. ${ }^{26}$

of undetermined significance (MGUS) to SMM, and patients with SMM spend less time in this state. Laboratory test results should be periodically evaluated for SMM and MGUS based on current consensus. Currently, the best strategy for high-risk SMM patients was involving patients in clinical trials. However, with the current COVID-19 pandemic, many trials are not accepting new patients, and thus these patients should be monitored and observed..$^{24,25}$

MGUS patients should be evaluated regularly to detect early transformation to initiate the treatment, minimize major complications, and prolong survival. Testing of M-proteins can be added for other routine medical tests. However, in this difficult situation, the priority to follow up is not listed as high priority. ${ }^{26}$ Further information can be seen in - Table 4.

\section{Approach to Stable Myeloma Patients or in Maintenance}

Patients who are stable on maintenance therapy with no major side effects should continue their treatment. If the patient is on dexamethasone, it is recommended to taper it down with the goal of discontinuing it. These patients do not need to visit the clinic for 3 months. Monitoring should be conducted in the closest laboratory, and phone visits may be used for toxicity check. . $3,24^{24}$

\section{General Advice for Transplantation in MM Patients}

Visitors should be restricted in the transplant unit, and staff with influenza symptoms are advised to stay at home. The staff should be evaluated regarding the probability of getting infected. In areas with a possibility of high transmission in the community, postpone the hospital visits or change it by telemedicine consultations, if possible. The staffs need to be trained regularly in proper procedures. Nonurgent transplant procedures should be postponed. Limited approach to stem cell donors if (1) amidst the clearance and harvest, the donor become contracted; (2) the harvest could not be done due to the infected staff; ( 3 ) the border was closed and not possible
Table 4 Priorities for SMM and MGUS patients

\begin{tabular}{|l|l|l|}
\hline $\begin{array}{l}\text { High } \\
\text { priority }\end{array}$ & Medium priority & Low priority \\
\hline- & $\begin{array}{l}\text { Consider delaying } \\
\text { scheduled visits or } \\
\text { reducing clinic visits for } \\
\text { surveillance of patients } \\
\text { with high-risk SMM } \\
\text { (individualized decision } \\
\text { according to risk) and/or } \\
\text { perform scheduled visits } \\
\text { particularly for surveil- } \\
\text { lance by telemedicine } \\
\text { and local laboratory } \\
\text { tests if possible }\end{array}$ & $\begin{array}{l}\text { Delay scheduled } \\
\text { visits for patients } \\
\text { with low-risk SMM or } \\
\text { MGUS and/or perform } \\
\text { by telemedicine and } \\
\text { local laboratory tests if } \\
\text { possible }\end{array}$ \\
\hline
\end{tabular}

Abbreviations: MGUS, monoclonal gammopathy of undetermined significance; SMM, smoldering multiple myeloma.

Source: European Society of Medical Oncology. ${ }^{26}$

to transport stem cells across it while the delivery options become limited. It is fully recommended to secure the stem cell produced by cryopreservation prior to conditioning. ${ }^{21,27}$

Patients awaiting ASCT were recommended to do home isolation for 14 days before the beginning of conditioning, and hospital visit is avoided. They should be evaluated for COVID-19 infection and the results must be negative in spite of any influenza symptoms. If the COVID-19 testing was positive, consideration must be made based on the risk of disease progression. For patients with low-risk disease, the ASCT could be postponed. On the other hand, transplant should be postponed until the patient has fully recovered with no symptoms left and has been tested with two negative subsequent PCR test at least 1 week apart. ${ }^{21,27,28}$

\section{Advice for Patients Who Have Recently Received ASCT}

The aim is to prevent the infection since patients in the early posttransplant period, those with graft versus host disease, and those with chronic pulmonary complications have high vulnerability. The recommendation is similar to the general 
recommendation for cancer patients. Preventive measures should be implemented to limit the risk of exposure toward the infected individuals, such as perform hand hygiene practice, cough etiquette, physical distancing, mask use, cleaning surfaces, and avoiding sharing objects. Travel if absolutely necessary only and by a private car when possible. Diagnostic procedures should follow local guidelines..$^{21,28}$

\section{Supportive Care}

It is not recommended to change supportive care in the midst of different phases of myeloma treatment, excluding the bisphosphonate prescription. Bisphosphonates use can be postponed for patients with sign of neither active bone disease nor hypercalcemia. It is recommended to use zoledronate every 3 months in consideration of the interruption if patients have achieved full response and have been treated with bisphosphonates for a minimum of 2 years. The indication of the antithrombotic agents, acyclovir, and sulfa as prophylaxis remains the same as before the COVID-19 pandemic and should be amenable to the treatment phase and combination drugs in use. Influenza and pneumococcal vaccines are essential. Mask use and good hand hygiene are compulsory. ${ }^{23}$

\section{Management of COVID-19 in a Myeloma Patient}

One case report of MM patient has been reported from Hefei, China. The patient had a history of symptomatic MM (immunoglobulin A lambda) around 5 years before. He was diagnosed with COVID-19 infection using a PCR swab test. The patient was successfully treated with tocilizumab $8 \mathrm{mg} / \mathrm{kg}$ body weight on day 9 of hospitalization because of worsening lung function. The other drugs were antiviral umifenovir $200 \mathrm{mg}$ tablet orally three times daily and methylprednisolone $40 \mathrm{mg}$ from day 1 to 5 . He was recovered on day $19 .{ }^{29}$ There is still limited evidence to recommend tocilizumab using in MM patients. Further randomized controlled trials are needed to evaluate drugs for COVID-19 infection in MM patients..$^{22,30}$

Considering that myeloma and COVID-19 shared common risk factors for venous thromboembolism, there is an association between coagulopathy in COVID-19 and increased death. In patient with COVID-19 and coagulopathy, distinctive findings could be found, such as increased D-dimer concentration, a relatively modest decrease in platelet count, and a prolonged prothrombin time. ${ }^{15}$ The International Thrombosis Society recommended giving anticoagulant prophylaxis in hospitalized cancer patients and to those who came with acute medical conditions throughout hospitalization. ${ }^{31}$ Weight-adjusted anticoagulant prophylaxis using low-molecular-weight heparin is recommended in hospitalized COVID-19, unless it is contraindicated, and should be continued after hospital discharge. ${ }^{32}$

\section{Patients in Clinical Trial}

The recommendation of the authorities in each country should be adhered to. Careful evaluation is needed to include new patients by carefully weighing benefits and risks.

Patients who have been participating in a study should continue. Options to decrease the frequency of clinical visits through telemedicine, preventing visits only done for the purpose of correlative studies unless required for safety assessment, and when possible shipping oral investigational drugs to the patient. Alternative bridging therapies should be considered until the COVID-19 pandemic situation improves. ${ }^{22}$

\section{International Consensus Recommendation}

There were recommendations from the International Myeloma Foundation, IMS, Multiple Myeloma Research Foundation, European Bone Marrow Transplant, American Society for Blood and Marrow Transplantation, European Hematology Association, and American Society of Hematology regarding the management of myeloma patients.

\section{Conclusion}

Myeloma societies in the world have released recommendations related to the management of myeloma patients. Nonetheless, evidence support for the recommendations is lacking. The international recommendations may not fully work due to local restrictions, availabilities, and limitations. The experience will be growing during this pandemic. The European Society for Medical Oncology (ESMO) has taken the initiative to undergo ESMO-CoCARE Registry ${ }^{33}$ to quickly gather data and information from health care professionals about the treatment approach, specifically focusing on the impact of COVID-19 on cancer patients. Another observational or clinical trial should be conducted along with increasing numbers of cancer patients contracting COVID-19.

\section{Conflict of Interest}

None declared.

\section{References}

1 World Health Organization. Coronavirus Disease (COVID-19): Situation Report-120. Available at: https://www.who.int/ docs/default-source/coronaviruse/situation-reports/2020051 9-covid-19-sitrep-120.pdf?sfvrsn=515cabfb_2. Accessed April 23, 2020

2 Moreau P, San Miguel J, Sonneveld P, et al. Multiple myeloma: ESMO clinical practice guidelines for diagnosis, treatment, and follow up. Ann Oncol 2017;28(Suppl 4):iv51-iv61

3 Palumbo A, Bringhen S, Ludwig H, et al. Personalized therapy in multiple myeloma according to patient age and vulnerability: a report of the European Myeloma Network (EMN) Blood 2011;118(17):4519-4529

4 Mian H, Grant SJ, Engelhardt M, et al. Caring for older adults with multiple myeloma during the COVID-19 pandemic perspective from the International forum for optimizing care of older adults with myeloma. J Geriatr Oncol 2020;11(5):764-768

5 Garnica M, Maiolino A. COVID and hematology: special considerations regarding patient safety, gold standard therapies and safety for health care professionals. Hematol Transfus Cell Ther 2020;42(2):111-112

6 Wang H, Zhang L. Risk of COVID-19 for patients with cancer. Lancet Oncol 2020;21(4):e181

7 Liang W, Guan W, Chen R, et al. Cancer patients in SARS-CoV-2 infection: a nationwide analysis in China. Lancet Oncol 2020;21(3):335-337

8 Moujaess E, Kourie HR, Ghosn M. Cancer patients and research during COVID-19 pandemic: A systematic review of current evidence. Crit Rev Oncol Hematol 2020;150:102972 
9 He W, Chen L, Chen L, et al. COVID-19 in persons with haematological cancers. Leukemia 2020;34(6):1637-1645

10 Tadjoedin $\mathrm{H}$, Reksodiputro AH, Toruan $\mathrm{T}$, et al. Multiple myeloma in Indonesia. Indonesian J Cancer 2011;5(2):76-81

11 Willan J, Eyre TA, Sharpley F, Watson C, King AJ, Ramasamy K. Multiple myeloma in the very elderly patient: challenges and solutions. Clin Interv Aging 2016;11:423-435

12 Gregersen H, Vangsted AJ, Abildgaard N, et al. The impact of comorbidity on mortality in multiple myeloma: a Danish nationwide population-based study. Cancer Med 2017;6(7):1807-1816

13 Cesarman-Maus G, Braggio E, Fonseca R. Thrombosis in multiple myeloma (MM) Hematology 2012;17(Suppl 1):S177-S180

14 Li X, Xu S, Yu M, et al. Risk factors for severity and mortality in adult COVID-19 inpatients in Wuhan. J Allergy Clin Immunol 2020;146(1):110-118

15 Levi M, Thachil J, Iba T, Levy JH. Coagulation abnormalities and thrombosis in patients with COVID-19. Lancet Haematol 2020;7(6):e438-e440

16 Paterson C, Gobel B, Gosselin T, et al. Oncology nursing during a pandemic: critical reflections in the context of COVID-19. Semin Oncol Nurs 2020;36(3):151028

17 Willan J, King AJ, Hayes S, Collins GP, Peniket A. Care of haematology patients in a COVID-19 epidemic. Br J Haematol 2020;189(2):241-243

18 Saini KS, de Las Heras B, de Castro J, et al. Effect of the COVID-19 pandemic on cancer treatment and research. Lancet Haematol 2020;7(6):e432-e435

19 Mayor S. COVID-19: impact on cancer workforce and delivery of care. Lancet Oncol 2020;21(5):633

20 Al-Quteimat OM, Amer AM. The impact of the COVID-19 pandemic on cancer patients. Am J Clin Oncol 2020;43(6):452-455

21 Multiple Myeloma Hub. COVID-19 and EBMT recommendations for patients with hematological malignancies. Available at: https://multiplemyelomahub.com/medicalinformation/covid-19-and-ebmt-recommendations-forpatients-with-hematological-malignancies. Accessed May 23, 2020

22 International Myeloid Society. International Myeloma Society recommendation for the management of myeloma patients during the COVID-19 pandemic. Available at: https:// cms. cws.net/ content/ beta.myelomasociety.org/ files/ IMS\%20recommendations\% 20for\% 20Physicians\% 20Final.pdf. Accessed April 23, 2020

23 Hungria V, Garnica M, Crusoé EQ et al. Managing patients with multiple myeloma during the COVID-19 pandemic: recommendations from an expert panel - ABHH Monoclo- nal Gammopathies Committee. Hematol Transfus Cell Ther 2020;42(3):200-205

24 Al Saleh AS, Sher T, Gertz MA. Multiple myeloma in the time of COVID-19. Acta Haematol 2020;1-7

25 Bergstrom DJ, Kotb R, Louzada ML, et al. Consensus guidelines on the diagnosis of the multiple myeloma and related disorders: recommendations of the Myeloma Canada Research Network Consensus Guidelines Consortium. Clin Lymphoma Myeloma Leuk 2020(7):e352-e367

26 European Society of Medical Oncology. ESMO management and treatment adapted recommendations In the COVID-19 era: multiple myeloma. Available at: https://www.esmo. org/guidelines/cancer-patient-management-during-thecovid-19-pandemic/haematological-malignancies-multiplemyeloma- in-the-c ovid-19-era. Accessed May 24, 2020

27 Ljungman P, Mikulska M, de la Camara R, et al. The challenge of COVID-19 and hematopoietic cell transplantation; EBMT recommendations for management of hematopoietic cell transplant recipients, their donors, and patients undergoing CAR T-cell therapy. Bone Marrow Transplant 2020;2020:1-6

28 Sahu KK, Jindal V, Siddiqui AD, Cerny J. Facing COVID-19 in the hematopoietic cell transplant setting: a new challenge for transplantation physicians. Blood Cells Mol Dis 2020;83102439

29 Zhang X, Song K, Tong F, et al. First case of COVID-19 in a patient with multiple myeloma successfully treated with tocilizumab. Blood Adv 2020;4(7):1307-1310

30 Galimberti S, Baldini C, Baratè C, et al. The CoV-2 outbreak: how hematologists could help to fight Covid-19. Pharmacol Res 2020;157:104866

31 Key NS, Khorana AA, Kuderer NM, et al. Venous thromboembolism prophylaxis and treatment in patient with cancer: ASCO Clinical Practice Guideline Update. J Clin Oncol 2020;38(5):496-520

32 Bikdeli B, Madhavan MV, Jimenez D, et al; Global COVID-19 Thrombosis Collaborative Group, Endorsed by the ISTH, NATF, ESVM, and the IUA, Supported by the ESC Working Group on Pulmonary Circulation and Right Ventricular Function. COVID-19 and thrombotic or thromboembolic disease: implications for prevention, antithrombotic therapy and follow up. J Am Coll Cardiol 2020;75(23):2950-2973

33 European Society of Medical Oncology. ESMO-CoCARE registry. Available at: https://www.esmo.org/covid-19-and-cancer/ collaborating-on-registries-studies-and-surveys/esmococare-registry. Accessed April 23, 2020 